\title{
BMJ Open Reduced magnetisation transfer ratio in cognitively impaired patients at the very early stage of multiple sclerosis: a prospective, multicenter, cross-sectional study
}

\author{
J H Faiss, ${ }^{1}$ D Dähne, ${ }^{1} \mathrm{~K}$ Baum, ${ }^{2} \mathrm{R}$ Deppe,${ }^{3} \mathrm{~F}$ Hoffmann, ${ }^{3}$ W Köhler, ${ }^{4}$ A Kunkel, ${ }^{1}$ \\ A Lux, ${ }^{5}$ M Matzke, ${ }^{5}$ I K Penner, ${ }^{6}$ M Sailer, ${ }^{5}$ U K Zettl $^{7}$
}

To cite: Faiss JH, Dähne D, Baum K, et al. Reduced magnetisation transfer ratio in cognitively impaired patients at the very early stage of multiple sclerosis: a prospective, multicenter, cross-sectional study. BMJ Open 2014;4:e004409. doi:10.1136/bmjopen-2013004409

- Prepublication history for this paper is available online. To view these files please visit the journal online (http://dx.doi.org/10.1136/ bmjopen-2013-004409).

Received 29 November 2013 Revised 24 February 2014 Accepted 27 February 2014

CrossMark

For numbered affiliations see end of article.

Correspondence to

$\mathrm{J}$ H Faiss,

j.faiss@asklepios.com

\section{ABSTRACT}

Objectives: Cognitive impairment belongs to the core symptoms in multiple sclerosis (MS) and can already be present at the very early stages of the disease. The present study evaluated cognitive functioning after the first clinical presentation suggestive of MS and brain tissue damage in a non-lesion focused MRI approach by using magnetisation transfer imaging (MTI).

Setting and participants: 47 patients (15 men and 32 women; mean age: 31.17 years) after the first clinical event suggestive of MS were recruited in six different MS centres in Germany and underwent a neuropsychological test battery including tests for attention, memory and executive function as well as depression and fatigue. MTI and conventional MRI measures (T1/T2 lesion load) were assessed. In addition, Magnetisation Transfer Ratio (MTR) maps were calculated. Primary outcome measure was the investigation of cognitive dysfunction in very early MS in correlation to MRI data.

Results: $55.3 \%$ of patients with MS failed at least one test parameter. Specifically, $6 \%$ were reduced in working memory, $14.9 \%$ in focused attention, $25.5 \%$ in figural learning and up to $14.9 \%$ in executive function. When the sample was subdivided into cognitively impaired and preserved, MTR scores within the cognitively impaired subgroup were significantly lower compared with the preserved group ( $\mathrm{t}(43)$ $\left.=2.346, p=0.02^{*}\right)$. No significant differences between the two groups were found in T2-weighted and T1-weighted lesion volume.

Conclusions: After the first MS-related clinical event, $55.3 \%$ of patients showed distinct cognitive deficits. Cognitively impaired patients had significantly lower whole brain MTR, but no differences in focal brain lesion volumes supporting the idea that early cognitive deficits may be related to diffuse loss of brain tissue integrity.

\section{INTRODUCTION}

The prevalence of cognitive deficits in multiple sclerosis (MS) ranges between $43 \%$ and

\section{Strengths and limitations of this study}

- The present prospective, cross-sectional, multicenter study was performed to investigate cognitive functioning at a very early stage of multiple sclerosis (by using a neuropsychological test battery) and the relation to brain tissue damage in a non-lesion focused MRI approach by using magnetisation transfer imaging (MTI).

- Using a strict definition of cognitive impairment (2 SDs below the normative sample) about $55 \%$ showed deficits especially in figural learning, focused attention and executive function and these patient-subgroup also showed significantly lower MTR scores compared with the cognitively preserved subgroup of patients.

- The conclusion was drawn that early cognitive deficits are related to diffuse loss of brain tissue integrity.

- Cognitive status should be included in treatment decisions, independent of physical disability as a marker for disease severity and progression.

- Cognition and MTI data from controlled longitudinal studies are rare, therefore follow-up assessment of cognitive function in relation to MRI parameters is required.

$65 \%$, depending on various research settings and characteristics of study samples. ${ }^{12}$ It is assumed that the MS-induced inflammatory demyelination and axonal damage may contribute to the cognitive decline. Other contributing factors are advanced age, low IQ or educational level and depression or fatigue. ${ }^{3}$ Cognitive dysfunction has a profound effect on maintaining employment, daily-living activities, social life, ability to drive and benefits from inpatient rehabilitation. ${ }^{13-8}$

Whereas intelligence, language, semantic memory and attention span are widely preserved, complex attention, information 
processing speed, verbal and visuospatial memory and executive functions are frequently involved. More specifically with regard to memory functions, explicit and episodic memory as part of long-term memory as well as short-term "working memory" are commonly affected. ${ }^{1}$

Reports about cognitive dysfunction already present at the stage of the first clinical event suggestive of MS are growing. ${ }^{9-18}$ Previous work shows that patients with MS in the early stage of the disease performed significantly lower on neuropsychological assessment compared to healthy controls. ${ }^{3} 4$ 9-12 1920 Often studies used only short neuropsychological test batteries, which were not sensitive enough to detect impairment in the study population of clinically isolated syndrome (CIS) or patients with early MS. ${ }^{19}{ }^{20}$ Furthermore, methodological problems like a diffuse definition of neuropsychological impairment, lack of consideration of depression and fatigue as covariates or lack of healthy controls to detect practice effect reduce the informative value of such studies.

Clinical trials on neuroimaging in patients at the point of first clinical event in correlation to cognitive dysfunction are rare. ${ }^{19}{ }^{20}$ In other MS subtypes, cross-sectional studies with conventional MRI demonstrated conflicting results between cognitive dysfunction and cerebral lesion load in T2-weighted and T1-weighted sequences including corpus callosum lesions, ${ }^{21}{ }^{22}$ juxtacortical lesions ${ }^{23}$ and lesions in the prefrontal cortex. ${ }^{24}$ More advanced MRI techniques such as Magnetisation Transfer Ratio (MTR) allow detection of brain tissue involvement correlating with myelin and axonal density. ${ }^{2526}$ MTR is a sensitive parameter to quantify the integrity of myelinated white matter in patients with MS including demyelination and remyelination even in the absence of axonal loss. This technique has been used in the past to assess the global burden of occult diseases using histograms or overall mean MTR values. The decrease of the mean MTR of cortical and subcortical regions was previously related to poorer performance on cognitive tests ${ }^{19} 27$ and impaired sustained attention and concentration ${ }^{28} 29$ in relapsing-remitting MS. The aim of our study was to corroborate the previous reports of this underestimated clinical finding in early disease stage and to substantiate the cognitive deficits by using MRI in a conventional versus a more advanced non-lesion focused way that potentially better reflects the underlying clinicopathological mechanism especially very early in the disease progress.

\section{METHODS}

\section{Participants}

Forty-seven patients (15 men and 32 women; mean age: 31.17 years) after the first clinical event suggestive of MS were recruited in six different MS centres for the study (Halle: $\mathrm{N}=11$, Hennigsdorf: $\mathrm{N}=6$, Magdeburg: $\mathrm{N}=5$, Rostock: $\mathrm{N}=10$, Teupitz: $\mathrm{N}=7$ and Wermsdorf: $\mathrm{N}=8$ ). Patients were included into the study directly after the diagnosis of MS or CIS was established and after checking the inclusion and exclusion criteria. Major exclusion criteria were current alcohol or substance abuse, history of head injury or any other medical condition affecting cognition. Furthermore participants were excluded if they had severe motor or visual impairments that might interfere with cognitive testing. All patients were treatment-naive. Disease modifying drugs prior to study inclusion were defined as exclusion criteria.

\section{MRI}

MRI was conducted for all patients at the MS centre, Magdeburg. MRI was performed using a neurooptimised 1.5-T GE Signa Horizon LX scanner with the standard quadrature head coil (General Electric, Milwaukee, Wisconsin, USA). Protocol for MTI consisted of a PD-weighted SE sequence (TR 2600, TE 20, 256×256) with and without a preparing saturation pulse $(1200 \mathrm{~Hz}$ off-resonance, 1180 flip-angle, $16 \mathrm{~ms}$ ). Forty-eight slices of $3 \mathrm{~mm}$ thickness aligned along the AC-PC line were acquired. Image postprocessing included calculation of MTR maps and an intersequence correction of movement with the automated image registration package rigid body model $\left(\mathrm{AIR}^{30}\right)$.

T1-weighted sequences ( $3 \mathrm{~mm}$ slices, FOV 250, TR $700 \mathrm{~ms}$ ) were performed without and with $0.1 \mathrm{mmol} / \mathrm{kg}$ bodyweight Gd-DTPA (3 mm slices, TR $3000 \mathrm{ms,}$ TE100 ms). Additionally, T2-weighted images were assessed (3 mm slices, TR $3000 \mathrm{~ms}$, TE100 ms). Lesion volume quantification was performed on T2-weighted and on T1-weighted images using a semiautomated, local contour technique. T1 lesions were identified as hypointense areas on the T1-weighted scans and confirmed on a T2-weighted scan as lesions. The semiquantitative lesion load measurement was performed using a highly reproducible ${ }^{31} 32$ threshold technique based on the local environmental intensity of the lesion (DispImage software package supplied by Dave Plummer, University College London, UK).

By application of an additional off-resonance HF impulse during a proton density-weighted imaging sequence the magnetisation of the immobile protons is partially saturated. Driven by relaxation processes, magnetisation is transferred from the mobile proton pool to the immobile one. The resulting signal attenuation in the mobile pool gives a signal reduction by imaging the pulse sequence with MT pulse. The signal reduction depends on tissue properties (especially the content of different macromolecules) and image sequence parameters. In two independent imaging sequences with (MT) and without (noMT) a saturation pulse the magnetisation transfer can be expressed as an MTR calculated voxel by voxel: MTR= (noMT-MT)/noMT in percent. Calculations were performed with MATLAB (MathWorks). Lesion and cortex were included to obtain an overall measure for brain parenchymal integrity.

\section{Neuropsychological assessment}

Neuropsychological assessment was performed 90-180 days after the first clinical event because at the point of 
neuropsychological testing all patients had to be relapsefree and without corticosteroid treatment. The interval between neuropsychological assessment and MRI was no longer than 14 days. Neuropsychological tests were performed by neuropsychologists. The used test procedure was selected by means of high objectivity (independence of rater). Before study start, neuropsychologists were instructed to use the same test order and instructions to patients.

The neuropsychological battery (table 1 ) was administered in two test parts with a $15 \mathrm{~min}$ break in between. The sequential order of tests within each test part was kept constant. The battery comprised attention tasks that are part of a computerised Attention Test Battery $\left(\mathrm{TAP}^{33}\right.$ ) and the Symbol Digit Modalities Test $\left(\mathrm{SDMT}^{34}\right)$, the Verbal Learning and Memory Test $\left(\mathrm{VLMT}^{35}\right)$, the Visual Learning and Memory Test for Neuropsychological Assessment (DCS-a Wolfram version ${ }^{36}$ ) and measures of executive functions, such as the Wisconsin Card Sorting Test (WCST, Nelson version ${ }^{37}$ ) and the Regensburger Word Fluency Test (RWT, animals, S-words, G/R change $\left.{ }^{38}\right)$. In addition, a recognition vocabulary test was used to assess the premorbid intelligence (german vocabulary scale, $\mathrm{WST}^{39}$ ). Finally, participants completed self-reported instruments for depression (German version of the 'Center for Epidemiological Studies' Depression Scale, ADS-L, ${ }^{40}$ ), fatigue (the Modified Fatigue Impact Scale, MFIS ${ }^{41}$ ) and quality of life (Functional Assessment of Multiple Sclerosis, FAMS ${ }^{42}$ ). The MFIS consists of 21 statements regarding fatigue, cut-off was a total value above 22 points. Depressive symptoms were assessed using the ADS-L. Cut-off was a total value above 23 points. Further, all participants were examined by means of the Multiple Sclerosis Functional Composite $\left(\mathrm{MSFC}^{43}\right)$ and the Expanded Disability Status Scale (EDSS). ${ }^{44}$ All patients gave written informed consent prior to inclusion in the study. The present study was conducted in accordance with the declaration of Helsinki and has been approved by the appropriate ethics committee of Brandenburg. Details that might disclose the identity of the participants were omitted.

\begin{tabular}{|c|c|}
\hline PART 1 & PART 2 \\
\hline $\begin{array}{l}\text { SDMT } \\
\text { WCST-Nelson } \\
\text { ADS-L† } \\
\text { VLMT (recall, recognition) }\end{array}$ & $\begin{array}{l}\text { DCS_-Wolfram* } \\
\text { TAP_-Divided Attention } \\
\text { TAP_-Cognitive Flexibility } \\
\text { RWT (animals, S-words, G/R } \\
\text { WST }\end{array}$ \\
\hline \multicolumn{2}{|c|}{$\begin{array}{l}\text { *Visual Learning and Memory Test for Neuropsychological } \\
\text { Assessment. } \\
\text { †Depression Scale. } \\
\text { fTest for assessing intellectual capabilities. } \\
\text { VLMT, Verbal Learning and Memory Test; TAP, Tests of attentiona } \\
\text { performance; SDMT, Symbol Digit Modalities Test; WCST, } \\
\text { Wisconsin Card Sorting Test; RWT, Regensburger Word Fluency } \\
\text { Test. }\end{array}$} \\
\hline
\end{tabular}

\section{DATA EVALUATION AND ANALYSIS}

The presented study was an exploratory pilot study with no sample size calculation. Individual performance on each of the neuropsychological tests was evaluated against standardised data. Test scores 2 SDs below the normative sample (ie, $\mathrm{PR}<2.3, \mathrm{~T}<30$ ) were considered to reflect impaired performance. Statistical analyses were calculated with the Statistical Package for the Social Sciences (SPSS Inc, Chicago, Illinois, USA) and by an independent biometrical institute. Patients with and without cognitive dysfunction were compared using $\mathrm{t}$ tests or Mann-Whitney $\mathrm{U}$ tests for independent samples. Pearson's $\chi^{2}$ tests were used to compare the observed frequencies of gender, educational level and handedness between the two groups (cross-over-tables). Correlations between cognitive parameters and clinical parameters were calculated by means of non-parametric rank correlations (Spearman) or product-moment correlations (Pearson). The non-parametric Mann-Whitney test was used for comparisons of lesion volumes of the cognitively impaired and unimpaired patients with MS. Mean MTR values were compared using t tests for independent samples. A significance $\alpha$ level of 0.05 for minimum was predetermined.

\section{RESULTS}

\section{Population}

Table 2 summarises demographic and clinical characteristics of all participants and of the two subgroups (cognitively impaired/cognitively preserved). Mean disease duration of the overall group was 1.56 months $( \pm 1.25)$ at the point of study inclusion. At the time of neuropsychological testing and MR investigation (90-180 days after study inclusion), $77 \%$ of the patients were classified as CIS and 23\% as RRMS (relapsing remitting multiple sclerosis) according to McDonalds criteria. ${ }^{45}$ Regarding demographic and clinical parameters between the two subgroups no significant differences were observed (table 2).

\section{Cognitive functioning}

By means of cognitive testing our sample could be divided into the following two subgroups: $55.3 \% \quad(\mathrm{~N}=26)$ of patients who failed at least one test $(\geq 2 \mathrm{SD}$ of the normative data) and $44.7 \%(\mathrm{~N}=21)$ of patients who were cognitively unimpaired. Twenty-eight per cent of the whole sample failed in one test parameter, $17 \%$ failed in two test parameters and $11 \%$ failed in at least three test parameters. Results of the neuropsychological testing are presented in table 3 .

\section{Attention}

Compared with the normative sample, $14.9 \%$ of patients failed for divided attention and $6.4 \%$ for information processing speed and working memory measured by the Paced Auditory Serial Addition Test (PASAT as part of MSFC). 
Table 2 Demographic, clinical and MRI characteristics

\begin{tabular}{|c|c|c|c|}
\hline & All patients & $\begin{array}{l}\text { Patients with } \\
\text { cognitive deficits }\end{array}$ & $\begin{array}{l}\text { Patients without } \\
\text { cognitive deficits }\end{array}$ \\
\hline Patient number & 47 & $26(55.3 \%)$ & $21(44.7 \%)$ \\
\hline Gender m/f & $15 / 32$ & $10 / 16$ & $5 / 16$ \\
\hline Mean age in years & $31.17 \pm 8.89$ & $30.54 \pm 9.20$ & $31.95 \pm 8.64$ \\
\hline \multirow[t]{3}{*}{ Education in years (number) } & <10 years: 3 & $<10$ years: 0 & <10 years: 3 \\
\hline & 10 years: 25 & 10 years: 15 & 10 years: 10 \\
\hline & $>10$ years: 16 & $>10$ years: 9 & $>10$ years: 7 \\
\hline Handedness right/left & $40 / 3$ & $22 / 2$ & $18 / 1$ \\
\hline Verbal-IQ (WST: z score) & $0.03 \pm 0.59$ & $0.01 \pm 0.68$ & $0.07 \pm 0.46$ \\
\hline Mean disease duration (month) & $1.56 \pm 1.25$ & $1.41 \pm 0.85$ & $1.74 \pm 1.59$ \\
\hline Disease course $†$ & $\begin{array}{l}\text { CIS: } 76.6 \%(\mathrm{~N}=36) \\
\text { RRMS: } 23 \%(\mathrm{~N}=11)\end{array}$ & $\begin{array}{l}\text { CIS: } 76.9 \%(\mathrm{~N}=20) \\
\text { RRMS: } 23.1 \%(\mathrm{~N}=6)\end{array}$ & $\begin{array}{l}\text { CIS: } 76.2 \%(\mathrm{~N}=16) \\
\text { RRMS: } 23.8 \%(\mathrm{~N}=5)\end{array}$ \\
\hline Median EDSS (min/max) & $1.5(0 / 4.0)$ & $1.5(0 / 3.5)$ & $1.5(0 / 4.0)$ \\
\hline MSFC (M/SD) & $0.56 \pm 0.33$ & $0.55 \pm 0.32$ & $0.57 \pm 0.34$ \\
\hline T1-weighted lesion load $\ddagger$ (mean/median) ${ }^{i}$ & $1332.07 / 492.00$ & $1380.00 / 558.00$ & $1275.00 / 474.00$ \\
\hline T2-weighted lesion load (mean/median) ${ }^{\mathrm{i}}$ & $2793.65 / 1798.50$ & $2949.84 / 1734.00$ & $2607.71 / 1863.00$ \\
\hline Mean MTR (M/SD) $)^{\mathrm{iii}}$ & $47.69 \pm 0.97$ & $47.39 \pm 0.91$ & $48.03 \pm 0.94$ \\
\hline \multicolumn{4}{|c|}{$\begin{array}{l}\text { Significant differences between patient groups are marked and } p \text { values are displayed below: }{ }^{i} t(44)=-0.186, p=0.854 \mathrm{~ns} ;{ }^{i i} t(44)=-0.365 \text {, } \\
p=0.717 \mathrm{~ns} ;{ }^{i i t} \mathrm{t}(43)=2.346, p=0.02, \text { MTR data based on } 45 \text { patients, } 1 \text { patient did not complete the MRI investigation. } \\
\text { †Disease course at the time of neuropsychological testing and MR investigation. } \\
\text { †The T1-weighted lesion load is related to the volume of T1 hypointense lesions. } \\
\text { CIS, clinically isolated syndrome; EDSS, Expanded Disability Status Scale; MTR, magnetisation transfer ratio; MSFC, Multiple Sclerosis } \\
\text { Functional Composite. }\end{array}$} \\
\hline
\end{tabular}

\section{Memory}

Verbal learning and memory measures were preserved in nearly all patients. In contrast, $25.5 \%$ of the patients showed disturbed figural memory performance.

\section{Executive functions}

Patients of $8.5-14.9 \%$ showed deficits in verbal fluency but only $4.3 \%$ of patients made significantly more perseverative errors in the WCST compared to the normative sample.

\section{Intellectual ability}

A recognition vocabulary test (WST) was used to estimate premorbid intellectual abilities to consider the possible positive effect of 'cognitive reserve' on test performance. In our study population premorbid intelligence was averaged and between the subgroups (cognitively impaired and preserved patients) no significant differences were obtained (WST: z-norm: $\mathrm{M}=0.03 \pm 0.59$ ).

\section{Depressive mood}

Depression scores obtained from the ADS-L revealed that $11 \%$ of our patients showed clinically relevant depression. In the cognitively impaired subgroup $4.3 \%$ and in the cognitively preserved subgroup $6.3 \%$ were depressed but cognitive impairment and depression scores were not significantly associated $(\mathrm{t}(45)=1.51, \mathrm{p}=0.14)$.

\section{Fatigue}

Approximately $36 \%$ of patients showed evidence of clinically relevant fatigue. Twenty-three per cent of the cognitively impaired subgroup and $14.9 \%$ of the cognitively preserved subgroup were fatigued. $t$ Test analysis showed no significant differences regarding the occurrence of fatigue between the two subgroups $(\mathrm{t}(45)=1.01, \mathrm{p}=0.32)$.

\section{Disability measurement}

Median EDSS score in the overall group was 1.5 (range $0-4)$. Cognitively impaired patients did not show significant differences concerning EDSS $(\mathrm{t}(43)=-0.125$, $\mathrm{p}=0.90)$ and MSFC scores $(\mathrm{t}(45)=0.14, \mathrm{p}=0.89)$ when compared to unimpaired patients.

\section{Magnetisation transfer imaging and cognition}

Whole brain MTR was significantly lower in the cognitively impaired subgroup compared to the preserved patients $\left(\mathrm{t}(43)=2.346, \mathrm{p}=0.02^{*}\right)$. Regarding T1-weighted and T2-weighted lesion load no significant differences between the two subgroups were detectable. No significant correlations were found between MTR and EDSS $(\mathrm{r}=-0.09, \mathrm{p}=0.55)$.

\section{DISCUSSION}

The results indicate that after the first MS-related clinical event, up to $55.3 \%$ of patients showed distinct cognitive deficits in the domains of attention, figural learning and executive functions. According to the classification by Amato $e t a l,{ }^{4}$ who suggested an allocation due to severity of cognitive dysfunction: $28 \%$ of the patients were cognitively mildly disabled, $17 \%$ were moderately disabled and $11 \%$ were severely disabled. These results correspond to the prevalence rates usually obtained in more advanced MS stages. $^{2} 44647$ 
Table 3 Neuropsychological test results for the two patient groups divided with respect to cognitive deficits

\begin{tabular}{|c|c|c|c|c|}
\hline \multirow[b]{2}{*}{ Cognitive tests } & \multicolumn{2}{|l|}{ All patients } & \multirow{2}{*}{$\begin{array}{l}\text { Patients with cognitive } \\
\text { deficits } M(S D)\end{array}$} & \multirow{2}{*}{$\begin{array}{l}\text { Patients without cognitive } \\
\text { deficits M (SD) }\end{array}$} \\
\hline & $\bar{M}\left(\right.$ SD) ${ }^{\star}$ & 2SD (\%) & & \\
\hline \multicolumn{5}{|l|}{ Attention (TAP) } \\
\hline Tonic alertness & $252.87( \pm 44.83)$ & 4.3 & $256.27( \pm 47.63)$ & $248.67( \pm 41.88)$ \\
\hline Phasic alertness & $241.49( \pm 41.54)$ & 2.1 & $247.50( \pm 48.69)$ & $234.05( \pm 30.00)$ \\
\hline \multicolumn{5}{|l|}{ Divided attention } \\
\hline Speed & $689.39( \pm 78.01)$ & 14.9 & $712.64( \pm 84.66)$ & $660.60( \pm 58.85)$ \\
\hline Mistakes & $1.04( \pm 1.33)$ & 2.1 & $1.23( \pm 1.37)$ & $0.81( \pm 1.29)$ \\
\hline Omissions & $1.26( \pm 1.63)$ & 6.4 & $1.73( \pm 1.99)$ & $0.67( \pm 0.73)$ \\
\hline Cognitive flexibility & $756.62( \pm 147.23)$ & 2.1 & $770.29( \pm 148.18)$ & $739.69( \pm 147.86)$ \\
\hline SDMT & $59.96( \pm 10.07)$ & 2.1 & $56.96( \pm 10.10)$ & $63.67( \pm 8.92)$ \\
\hline PASAT (MSFC) & $47.87( \pm 9.86)$ & 6.4 & $46.85( \pm 10.38)$ & $49.14( \pm 9.26)$ \\
\hline \multicolumn{5}{|l|}{ Memory } \\
\hline \multicolumn{5}{|l|}{ VLMT } \\
\hline Learning & $57.94( \pm 7.55)$ & 0 & $58.23( \pm 7.54)$ & $57.57( \pm 7.73)$ \\
\hline Delayed recall & $12.53( \pm 1.89)$ & 0 & $12.27( \pm 1.95)$ & $12.86( \pm 1.80)$ \\
\hline Loss of information & $1.26( \pm 1.45)$ & 0 & $1.65( \pm 1.29)$ & $0.76( \pm 1.51)$ \\
\hline Recognition & $13.91( \pm 1.41)$ & 0 & $13.85( \pm 1.41)$ & $14.00( \pm 1.45)$ \\
\hline \multicolumn{5}{|l|}{ DCS } \\
\hline Immediate recall & $26.23( \pm 11.29)$ & 6.4 & $28.65( \pm 11.30)$ & $23.24( \pm 10.81)$ \\
\hline Learning score & $22.86( \pm 9.58)$ & 25.5 & $19.12( \pm 10.20)$ & $27.50( \pm 6.34)$ \\
\hline \multicolumn{5}{|l|}{ Executive function } \\
\hline WCST-Nelson† & $14.95( \pm 20.19)$ & 4.3 & $17.27( \pm 20.95)$ & $12.07( \pm 19.32)$ \\
\hline \multicolumn{5}{|l|}{ RWT } \\
\hline Animals & $37.64( \pm 11.04)$ & 14.9 & $34.15( \pm 11.17)$ & $41.95( \pm 9.45)$ \\
\hline S-words & $21.11( \pm 6.73)$ & 8.5 & $19.58( \pm 7.13)$ & $23.00( \pm 5.81)$ \\
\hline G/R-change & $19.81( \pm 5.90)$ & 10.6 & $17.38( \pm 5.58)$ & $22.81( \pm 4.92)$ \\
\hline \multicolumn{5}{|l|}{ Depression } \\
\hline ADS-L & $11.23( \pm 7.72)$ & $10.6 \ddagger$ & $9.73( \pm 7.20)$ & $13.10( \pm 8.10)$ \\
\hline \multicolumn{5}{|l|}{ Fatigue } \\
\hline MFIS & $19.72( \pm 15.62)$ & $36.2 \S$ & $17.65( \pm 14.00)$ & $22.29( \pm 17.43)$ \\
\hline \multicolumn{5}{|l|}{ Premorbid IQ } \\
\hline WST & $29.87( \pm 4.29)$ & 0 & $29.46( \pm 4.98)$ & $30.38( \pm 3.28)$ \\
\hline \multicolumn{5}{|c|}{$\begin{array}{l}\text { *Mean and SD. } \\
\text { tper cent perseverative errors. } \\
\text { tper cent clinically relevant depression. } \\
\text { \$per cent clinically relevant fatigue. } \\
\text { ADS-L, German version of the Center for Epidemiological Studies Depression Scale; DCS, Visual Learning and Memory Test for } \\
\text { Neuropsychological Assessment; MFIS, Modified Fatigue Impact Scale; MSFC, Multiple Sclerosis Functional Composite; PASAT, Paced } \\
\text { Auditory Serial Addition Test; TAP, Attention Test Battery; RWT, Regensburger Word Fluency Test; VLMT, Verbal Learning and Memory } \\
\text { Tests; SDMT, Symbol Digit Modalities Test; WST, german vocabulary scale. }\end{array}$} \\
\hline
\end{tabular}

The proportion of observed cognitive disorders in MS is very inconsistent in the literature due to a lack of standards in definition of cognitive impairment and in neuropsychological tests used. In this study a very conservative criterion for cognitive impairment (at least 2 SDs below the appropriate norm) was applied. The selected neuropsychological tests are well established tools providing high methodological standards for retest-reliability and validity. The SDMT and PASAT, one of the most widely used brief repeatable battery of neuropsychological tests $\left(\mathrm{BRB}-\mathrm{N}^{48}\right)$, were used to investigate sustained and complex attention as well as information-processing speed and working memory. Although in this study cohort performance on the SDMT did not account for the subdivision into cognitively impaired and preserved patients, the recently represented Brief International Assessment of Cognition for MS (BICAMS), which takes $15 \mathrm{~min}$ to complete and comprises the SDMT, a learning test (The California Verbal Learning Test) and a visuospatial memory test (The Brief Visuospatial Memory Test-Revised) can be recommend for use in daily clinical practice unless extensive cognitive analysis is not possible. ${ }^{49}$ Although, no significant correlations between depression or fatigue and cognitive impairment were observed, both were considered as parameters which can interfere with cognitive performance. The lack of correlations between cognition and fatigue or depression in contrast to results in other studies ${ }^{50} 51$ could be explained by the short disease duration and disease course of our study population. In the literature, the relationship between psychological status and cognition is still under discussion. ${ }^{52-54}$ Based on the results of this study, a neuropsychological assessment using a standardised test battery should 
routinely be conducted in the earliest stages of the disease even if the physical impairment is low. Furthermore cognitively impaired patients should be observed regularly during the disease course. The neuropsychological assessment should not be performed during a relapse or treatment with corticosteroids because both may cause increased deficits in attention or memory. ${ }^{55}{ }^{56}$ Recent research show that the definition of relapse is difficult and might be represented only by fatigue or gadolinium enhanced lesions without clinical symptoms; both could have a negative impact on test performance. ${ }^{57} 58$

The extent of physical disabilities as measured by EDSS and MSFC was not correlated with cognition, which is often described in the literature. ${ }^{10}{ }^{14}$ This can be explained by the fact that EDSS is not sensitive in determining cognitive disorders and physical and cognitive impairment occur independently from each other during the disease course. Our study population was only mildly disabled measured by EDSS and had a short disease duration. Cognition might be a sensitive marker especially at the onset of the disease. In addition no significant associations were found between MTR and EDSS. However, cognitively impaired patients had significantly lower MTR scores. MTR decrease may be an early sign for tissue changes related to impaired cognitive function while physical disability may be absent. Recently, reductions of cortical MTR have also been found to correlate with cognitive status in physically mildly disabled patients in the later stages of the disease.$^{59}{ }^{60}$ In contrast lesion load parameters, such as T2 lesion load, showed no association with overall cognitive decline in the patients, although white matter lesion formation is a hallmark in the pathology of MS. The dissociation of focal inflammatory lesions in the white matter from the clinical manifestations of relapses, disability and cognitive performance has been previously reported. ${ }^{21-23}$ In a recent study Deloire $e t a l^{19}$ found that diffuse brain damage measured by normal-appearing brain tissue MTR at the onset of the disease was the main predictor of cognitive changes over 7 years. Consequently a less lesion-focused view of MS especially in the workup of cognitive deficits is necessary. Since cognitive performance is heavily dependent on the integrity of neuronal network a lesion independent assessment of tissue integrity may at best reflect cognitive deficits. This study supports the hypothesis that cognitive decline in early MS is rather associated with impaired integrity of brain tissue as a result of generalised myelin destruction and axonal loss than with focal white matter pathology. Our results also indicate that nonconventional MRI techniques, for example, MTR, with increased specificity to more destructive aspects of MS pathology are able to reflect cognitive disturbances even at earliest stages of MS (mean disease duration 1.56 month). The evolution of pathological changes in brain tissue as depicted by a lower MTR in the overall cognitively impaired group may even start prior to the first clinical event. ${ }^{61}$
On the basis of our findings that show significant correlations between cognitive performance and decreased MTRs suggesting diffuse brain tissue changes in patients with early MS, ${ }^{62-64}$ the cognitive status should be included in treatment decisions, independent of physical disability as a marker for disease severity and progression. Neuropsychological tests may reveal clinically significant cognitive disability from the first presentation suggestive of MS.

\section{Author affiliations}

${ }^{1}$ Asklepios Fachklinikum Teupitz, Teupitz, Germany

${ }^{2}$ Klinik Hennigsdorf, Hennigsdorf, Germany

${ }^{3}$ Krankenhaus Martha-Maria Halle, Halle, Germany

${ }^{4}$ Fachkrankenhaus Hubertusburg, Wermsdorf, Germany

${ }^{5}$ Universitätsklinikum Magdeburg, Magdeburg, Germany

${ }^{6}$ Universität Basel, Basel, Schweiz

${ }^{7}$ Universität Rostock, Rostock, Germany

Acknowledgements The authors thank Biogenldec for assistance and partially funding the researches and the Biometric Department of University Magdeburg for conducting statistical analysis.

Contributors JHF, KB, FH, WK, MS and UKZ planned and designed the study. $\mathrm{DD}, \mathrm{RD}$ and $\mathrm{AK}$ made substantial contribution to acquisition of the neuropsychological data. MM and MS conducted the MR investigation and analysis of the MRI data. AL conducted statistical analysis. IKP made substantial contribution to analysis and interpretation of the data. KB, IKP, MM, MS, WK, AK, DD and JHF drafted sections of the manuscript. All authors revised it critically for important intellectual content and approved the final version of the manuscript.

Funding This study was partially funded by Biogenldec.

Competing interests None.

Patient consent Obtained.

Ethics approval Landesärztekammer Brandenburg.

Provenance and peer review Not commissioned; externally peer reviewed.

Data sharing statement No additional data are available.

Open Access This is an Open Access article distributed in accordance with the Creative Commons Attribution Non Commercial (CC BY-NC 3.0) license, which permits others to distribute, remix, adapt, build upon this work noncommercially, and license their derivative works on different terms, provided the original work is properly cited and the use is non-commercial. See: http:// creativecommons.org/licenses/by-nc/3.0/

\section{REFERENCES}

1. Amato MP, Zipoli V, Portaccio E. Cognitive changes in multiple sclerosis. Expert Rev Neurother 2008;8:1585-96.

2. Rao SM, Leo GJ, Bernardin L, et al. Cognitive dysfunction in multiple sclerosis. I. Frequency, patterns, and prediction. Neurology 1991;41:685-91.

3. Patti F. Cognitive impairment in multiple sclerosis. Mult Scler 2009;15:2-8.

4. Amato MP, Ponziani G, Pracucci G, et al. Cognitive impairment in early-onset multiple sclerosis. Pattern, predictors, and impact on everyday life in a 4-year follow-up. Arch Neurol 1995;52:168-72.

5. Beatty WW, Paul RH, Wilbanks SL, et al. Identifying multiple sclerosis patients with mild or global cognitive impairment using the Screening Examination for Cognitive Impairment (SEFCl). Neurology 1995;45:718-23.

6. Langdon DW, Thompson AJ. Multiple sclerosis: a preliminary study of selected variables affecting rehabilitation outcome. Mult Scler 1999;5:94-100.

7. Rao SM, Leo GJ, Ellington L, et al. Cognitive dysfunction in multiple sclerosis. II. Impact on employment, social functioning. Neurology $1991 ; 41: 692-6$. 
8. Schultheis MT, Garay E, DeLuca J. The influence of cognitive impairment on driving performance in multiple sclerosis. Neurology 2001:56:1089-94.

9. Achiron $A$, Barak $Y$. Cognitive impairment in probable multiple sclerosis. J Neurol Neurosurg Psychiatry 2003;74:443-6.

10. Schulz D, Kopp B, Kunkel A, et al. Cognition in the early stage of multiple sclerosis. J Neurol 2006;253:1002-10.

11. Simioni S, Ruffieux $C$, Bruggimann $L$, et al. Cognition, mood and fatigue in patients in the early stage of multiple sclerosis. Swiss Med Wkly 2007;137:496-501.

12. Zivadinov R, Sepcic J, Nasuelli D, et al. A longitudinal study of brain atrophy and cognitive disturbances in the early phase of relapsingremitting multiple sclerosis. J Neurol Neurosurg Psychiatry 2001;70:773-80.

13. Achiron A, Barak Y. Cognitive changes in early MS: a call for a common framework. J Neurol Sci 2006;245:47-51.

14. Audoin B, Duong MVA, Ranjeva J-P, et al. Magnetic resonance study of the influence of tissue damage and cortical reorganization on PASAT performance at the earliest stage of multiple sclerosis. Hum Brain Mapp 2005;24:216-28.

15. Feuillet L, Reuter F, Audoin B, et al. Early cognitive impairment in patients with clinically isolated syndrome suggestive of multiple sclerosis. Mult Scler 2007;13:124-7.

16. Fredrikson $\mathrm{S}$, Wicklein $\mathrm{E}$, Scherer $\mathrm{P}$, et al. Cognitive performance in early multiple sclerosis (MS): baseline data for CogniMS, a multinational longitudinal study. Neurology 2008;70(Suppl 1):PO4.174.

17. Glanz B, Holland C, Gauthier S, et al. Cognitive dysfunction in patients with clinically isolated syndromes or newly diagnosed multiple sclerosis. Mult Scler 2007;13:1004-10.

18. Potagas C, Giogkaraki E, Koutsis G, et al. Cognitive impairment in different MS subtypes and clinically isolated syndromes. J Neurol Sci 2008;267:100-6.

19. Deloire MSA, Ruet A, Hamel D, et al. MRI predictors of cognitive outcome in early multiple sclerosis. Neurology 2011;76:1161-7.

20. Khalil M, Enzinger C, Langkammer $\mathrm{C}$, et al. Cognitive impairment in relation to MRI metrics in patients with clinically isolated syndrome. Mult Scler 2011;17:173-80.

21. Camp SJ, Stevenson VL, Thompson AJ, et al. Cognitive function in primary progressive, transitional progressive multiple sclerosis: a controlled study with MRI correlates. Brain 1999;122:1341-8.

22. Rovaris M, Comi G, Filippi M. MRI markers of destructive pathology in multiple sclerosis-related cognitive dysfunction. J Neurol Sci 2006;245:111-16

23. Lazeron $\mathrm{RH}$, Langdon DW, Filippi M, et al. Neuropsychological impairment in multiple sclerosis patients: the role of (juxta)cortical lesion on FLAIR. Mult Scler 2000;6:280-5.

24. Foong J, Rozewicz L, Quaghebeur G, et al. Executive function in multiple sclerosis. The role of frontal lobe pathology. Brain 1997:120:15-26.

25. van Waesberghe $\mathrm{JH}$, Kamphorst W, De Groot C, et al. Axonal loss in multiple sclerosis lesions: magnetic resonance imaging insights into substrates of disability. Ann Neurol 1999:46:747-54

26. Schmierer K, Scaravilli F, Altmann DR, et al. Magnetization transfer ratio and myelin in postmortem multiple sclerosis brain. Ann Neurol 2004:56:407-15.

27. Rovaris M, Filippi M, Minicucci L. Cortical/subcortical disease burden and cognitive impairment in patients with multiple sclerosis. AJNR Am J Neuroradiol 2000;21:402-8.

28. Deloire MS, Salort E, Bonnet M, et al. Cognitive impairment as marker of diffuse brain abnormalities in early relapsing remitting multiple sclerosis. J Neurol Neurosurg Psychiatr 2005;76:519-26.

29. Summers MM, Fisniku LK, Anderson VM, et al. Cognitive impairment in relapsing-remitting multiple sclerosis can be predicted by imaging performed several years earlier. Mult Scler 2008;14:197-204.

30. Woods RP, Mazziotta JC, Cherry SR. MRI-PET registration algorithm. J Comput Assist Tomogr 1993;17:536-46.

31. Plummer D. Displmage: a display and analysis tool for medical images. Riv Neuroradiol 1992;5:488-95.

32. Molyneux PD, Tofts PS, Fletcher A, et al. Precision and reliability of measurement of change in MRI lesion volume in multiple sclerosis: a comparison of two computer assisted techniques. J Neurol Neurosurg Psychiatry 1998;65:42-7.

33. Zimmermann P, Fimm B. Testbatterie zur Aufmerksamkeitsprüfung, Version 2.1 2008; Psychologische Testsysteme, Vera Fimm, Herzogenrath.

34. Smith A. Symbol Digit Modalities Test. Los Angeles: Western Psychological Services, 2000,

35. Helmstaedter C, Lendt M, Lux S. Verbaler Lern- und Merkfähigkeitstest.Beltz, Göttingen: 2001.

36. Wolfram H, Neumann J, Wieczorek V. Psychologische Leistungstests in der Neurologie und Psychiatrie. Leipzig: Thieme, 1989:89-102.
37. Nelson HE. A Modified Card Sorting Test sensitive to frontal lobe defects. Cortex 1976;12:313-24.

38. Aschenbrenner S, Tucha O, Lange KW. Regensburger Wortflüssigkeits-Test, Handanweisung. Göttingen: Hogrefe, 2000.

39. Schmidt KH, Metzler P. Wortschatztest.Weinheim: Beltz Test, 1992.

40. Hautzinger M, Bailer M. Allgemeine Depressionsskala (ADS) Weinheim: Beltz Test, 1993.

41. Multiple Sclerosis Council for Clinical Practice Guidelines. Fatigue and multiple sclerosis: evidence-based management strategies for fatigue in multiple sclerosis. 1998.

42. Cella DF, Dineen K, Arnason B, et al. Validation of the functional assessment of multiple sclerosis quality of life instrument. Neurology 1996;47:129-39.

43. Cutter GR, Baier ML, Rudick RA, et al. Development of a multiple sclerosis functional composite as a clinical trial outcome measure. Brain 1999;122:871-82.

44. Kurtzke JF. Rating neurologic impairment in multiple sclerosis: an expanded disability status scale (EDSS). Neurol 1983;33:1444-52.

45. McDonald WI, Compston A, Edan G, et al. Recommended diagnostic criteria for multiple sclerosis: guidelines from the international panel on the diagnosis of multiple sclerosis. Ann Neurol 2001;50:121-7.

46. Amato MP, Ponziani G, Siracausa G, et al. Cognitive dysfunktion in early-onset multiple sclerosis. A reappraisal after 10 years. Arch Neurol 2001;58:1602-6.

47. Prosiegel M, Michael C. Neuropsychology and multiple sclerosis: diagnostic and rehabilitative approaches. J Neuropsychol Sci 1993;115:51-4.

48. Boringa JB, Lazeron $\mathrm{RH}$, Reuling IE, et al. The brief repeatable battery of neuropsychological tests: normative values allow application in multiple sclerosis clinical practice. Mult Scler2001;7:263-7.

49. Langdon DW, Amato MP, Boringa J, et al. Recommendations for a Brief International Cognitive Assessment for Multiple Sclerosis (BICAMS). Mult Scler J 2012;18:891-8.

50. Weinges-Evers N, Brandt AU, Bock M, et al. Correlation of self-assessed fatigue and alertness in multiple sclerosis. Mult Scler 2010;16:1134-40.

51. Andreasen AK, Spliid PE, Andersen $\mathrm{H}$, et al. Fatigue and processing speed are related in multiple sclerosis. Eur J Neurol 2010;17:212-18.

52. Arnett PA, Higginson $\mathrm{Cl}$, Randolph JJ. Depression in multiple sclerosis: relationship to planning ability. J Intern Neuropsychol Soc 2001;7:665-74.

53. Arnett PA, Higginson Cl, Voss WD, et al. Depression in multiple sclerosis: relationship to working memory capacity. Neuropsychology 1999;13:546-56.

54. Arnett PA, Higginson Cl, Voss WD, et al. Depression mood in multiple sclerosis: relationship to capacity-demanding memory and attentional functioning. Neuropsychology 1999;13:434-46.

55. Foong J, Rozewicz L, Quaghebeur G, et al. Neuropsychological deficits in multiple sclerosis after acute relapse. J Neurol Neurosurg Psychiatry 1998;64:529-32.

56. Oliveri RL, Sibilia G, Valentino $\mathrm{P}$, et al. Pulsed methylprednisolone induces a reversible impairment of memory in patients with relapsing-remitting multiple sclerosis. Acta Neurol Scand 1998:97:366-9.

57. Flachenecker $\mathrm{P}$, Meissner $\mathrm{H}$. Fatigue in multiple sclerosis presenting as acute relapse: subjective and objective assessment. Mult Scler 2008;14:274-7.

58. Bellmann-Stobl J, Wuerfel J, Aktas O, et al. Poor PASAT performance correlates with MRI contrast enhancement in multiple sclerosis. Neurology 2009;73:1624-7.

59. Filippi M, Rocca MA, Benedickt RHB, et al. The contribution of MRI in assessing cognitive impairment in multiple sclerosis. Neurology 2010;75:2121-8.

60. Amato MP, Portaccio E, Stromillo ML, et al. Cognitive assessment and quantitative magnetic resonance metrics can help to identify benign multiple sclerosis. Neurology 2008;71:632-8.

61. Davies GR, Altmann DR, Hadjiprocopis A, et al. Increasing normal-appearing grey and white matter magnetization transfer ratio abnormality in early relapsing-remitting multiple sclerosis. $J$ Neurol 2005;252:1037-44.

62. Feinstein A, Kartsounis LD, Miller DH, et al. Clinically isolated lesions of the type seen in multiple sclerosis: a cognitive, psychiatric and MRI follow up study. J Neurol Neurosurg Psychiatry 1992;55:869-76.

63. Feinstein A, Youl B, Ron M. Acute optic neuritis: a cognitive and magnetic resonance imaging study. Brain 1992;115:1405-15.

64. Filippi M, Tortorella C, Rovaris M, et al. Changes in the normal appearing brain tissue and cognitive impairment in multiple sclerosis. J Neurol Neruosurg Psychiatry 2000; 68:157-62. 